\title{
MUTAROTATION OF l-SORBOSE
}

\author{
By William Ward Pigman and Horace S. Isbell
}

\section{ABSTRACT}

Optical-rotation measurements are reported on carefully purified $l$-sorbose at 0.4 and $20^{\circ} \mathrm{C}$. In contradiction of the statements in various periodicals and text books, the results show that this sugar exhibits a small complex mutarotation.

Since the ketohexose, $l$-sorbose, has become of commercial importance, particularly as an intermediate in the synthesis of ascorbic acid, an accurate knowledge of its physical and chemical properties is desirable. The optical rotation of $l$-sorbose was studied by Lobry de Bruyn and Van Ekenstein, ${ }^{1}$ who reported that no mutarotation was observable. Although the effect of temperature, concentration, and other factors on the equilibrium specific rotation have been studied, ${ }^{2}$ it has been generally assumed, except for a statement by Riiber, ${ }^{3}$ that the sugar does not mutarotate or else that the mutarotation is too rapid to be detected. ${ }^{4}$

We have made a number of measurements of the optical rotatory power of pure samples of anhydrous $l$-sorbose ${ }^{5}$ in water solution and have found that neither of the earlier assumptions is correct, since the sugar exhibits a definite mutatotation in which the optical rotation increases slightly at first and then decreases, so that the initial and final rotations are not widely different. The observed change (about $0.7^{\circ}$ $\mathrm{S}$ ) is undoubtedly real and is not due to accidental impurities, because samples of the sugar which had been purified and then recrystallized $2,3,5$, and 6 times from water gave the same characteristic mutarotation. On account of its complex character the mutarotation cannot be represented by the usual first-order equation but requires an equation containing two exponential terms. The measurements and equations representing the reactions at both 20 and $0^{\circ} \mathrm{C}$ are given in table 1 .

1 M. M. C. A. Lobry de Bruyn and W. A. Van Ekenstein, Rec. trav. chim. 19, 6 (1900).

3 R. H. Smith and B. Tollens, Ber. deut. chem. Ges. 33, 1285 (1900).

3 C. N. Riiber, Saertrykk av Tidsskrift for kJemi og bergvesen, no. 10 , p. 16 (1932).

- Tollens-Elsner, Kurzes Handbuch der Kohlenhydrate, p. 383 (Johann Ambrosius Barth, Leipzig, 1935).

$\checkmark$ The material used was furnished through the courtesy of the Bureau of Chemistry and Soils, U. B. Department of Agriculture. 
TABLE 1.-Mutarotation of l-sorbose in water ${ }^{1}$

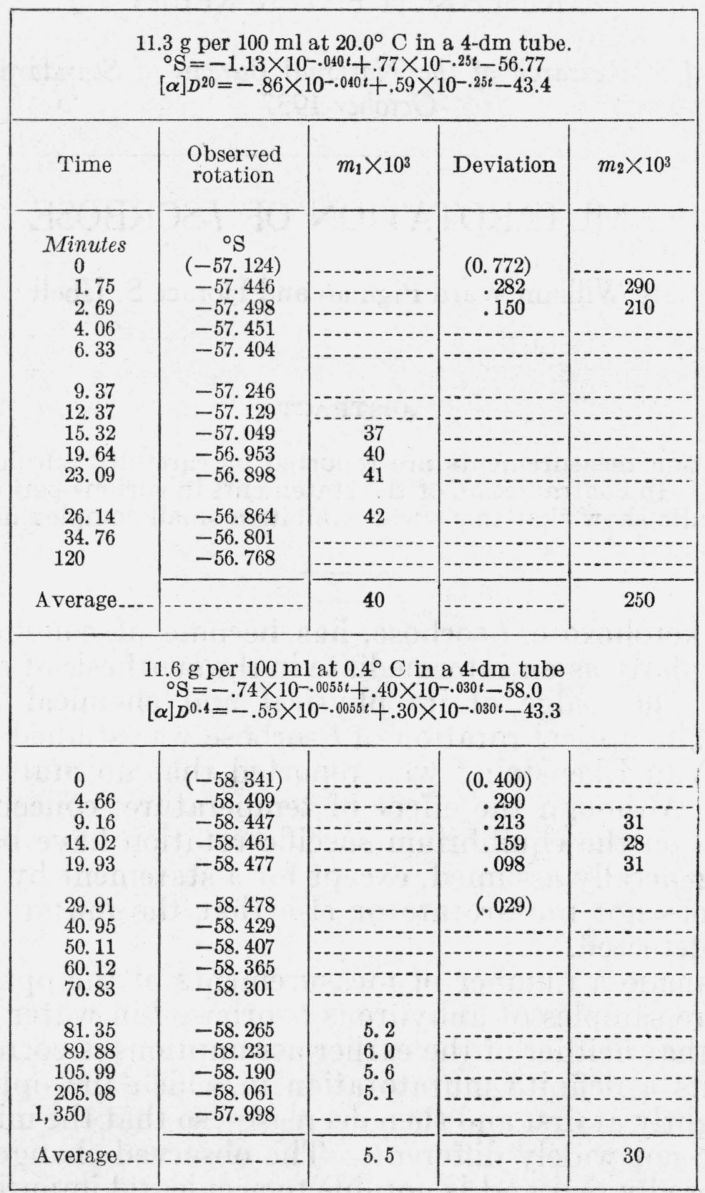

1 The equations and values for mutarotation constants, $m_{1}$, and $m_{2}$, are determined by the method described by Isbell and Pigman, J. Research NBS 18, 156 (1937) RP969. Each observed rotation represents the average of 10 consecutive readings.

The smallness of the mutarotation might arise from one of two possibilities: (1) Equilibrium might be established between isomers having only slightly different optical rotatory values, in which case the equilibrium solution would contain considerable quantities of these isomers, or (2) the known modification might greatly predominate in the equilibrium state and other modifications be present only in small quantities. In order to decide between these possibilities, solubility measurements were made of $l$-sorbose in water at $0^{\circ} \mathrm{C}$. An excess of finely powdered $l$-sorbose was shaken with ice water for 3 minutes and filtered; after standing until equilibrium was reached, the solution read $-127.52^{\circ} \mathrm{S}$ in a 4 -dm tube. A solution allowed to reach equilibrium at $0^{\circ} \mathrm{C}$ in the presence of an excess of $l$-sorbose read $-128.63^{\circ} \mathrm{S}$ in a 4 -dm tube. The small difference ( 0.87 percent) between the two values indicates that the equilibrium solution of 
$l$-sorbose is composed almost exclusively of that isomer which is known in the crystalline state.

The specific rotations for $l$-sorbose in water were found to be $[\alpha] D^{0.4}=-43.3$ and $[\alpha] D^{20}=-43.4(12 \mathrm{~g}$. of $l$-sorbose in $100 \mathrm{ml})$. The equilibrium appears to be only slightly affected by temperature. This behavior resembles that of glucose, as might be expected from the analogous structures of the two sugars. The equilibrium specific rotation in 50-percent (in volume) ethyl alcohol was found to be $[\alpha] D^{20}=-43.4\left(0.6067 \mathrm{~g}\right.$ made up to $25 \mathrm{ml}$ read $-12.18^{\circ} \mathrm{S}$ in a $4-\mathrm{dm}$ tube).

Washington, August 10, 1937. 